\title{
Enema Tablet Dosage Form
}

National Cancer Institute

\section{Source}

National Cancer Institute. Enema Tablet Dosage Form. NCI Thesaurus. Code C64871.

A tablet that is suspended in liquid prior to administration to the rectum. 